䖵 


\section{ISNM 108:}

International Series of Numerical Mathematics

Internationale Schriftenreihe zur Numerischen Mathematik

Série Internationale d'Analyse Numérique

Vol. 108

Edited by

K.-H. Hoffmann, München; H. D. Mittelmann, Tempe;

J. Todd, Pasadena

Springer Basel AG 


\section{H. Antes P. D. Panagiotopoulos The Boundary Integral Approach to Static and Dynamic Contact Problems}

Equality and Inequality Methods 
Authors

Prof. Dr. Heinz Antes

Institut für Angewandte

Mechanik

T.U. Braunschweig

D-W-3300 Braunschweig

Germany
Prof. Dr. Panagiotis D. Panagiotopoulos

Dept. of Civil Engineering

Aristotle University

GR-54006 Thessaloniki

Greece

and

Fakultät für Mathematik und Physik

RWTH Aachen

D-W-5100 Aachen

Germany

A CIP catalogue record for this book is available from the Library of Congress, Washington D.C., USA

\section{Deutsche Bibliothek Cataloging-in-Publication Data}

\section{Antes, Heinz:}

The boundary integral approach to static and dynamic contact problems: equality and inequality methods / H. Antes; P. D.

Panagiotopoulos. - Basel ; Boston ; Berlin : Birkhäuser, 1992

(International series of numerical mathematics ; Vol. 108)

ISBN 978-3-0348-9716-7 ISBN 978-3-0348-8650-5 (eBook)

DOI 10.1007/978-3-0348-8650-5

NE: Panagiotopoulos, Panagiotis D.:; GT

This work is subject to copyright. All rights are reserved, whether the whole or part of the material is concerned, specifically those of translation, reprinting, re-use of illustrations, broadcasting, reproduction by photocopying machine or similar means, and storage in data banks. Under $\S 54$ of the German Copyright Law where copies are made for other than private use a fee is payable to "Verwertungsgesellschaft Wort«, Munich.

(c) 1992 Springer Basel AG

Originally published by Birkhäuser Verlag Basel in 1992

Softcover reprint of the hardcover 1st edition 1992

Printed from the authors' camera-ready manuscript on acid-free paper ISBN 978-3-0348-9716-7 
Dedicated to the Memory of Professor Carl Heinz a Teacher, Friend and Colleague greatly missed 


\section{Contents}

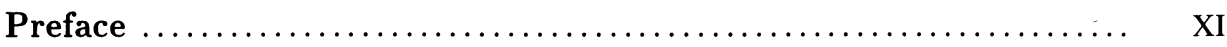

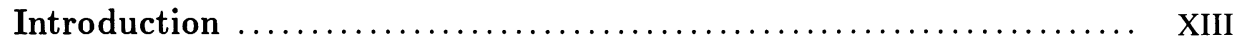

Guidelines for the Reader $\ldots \ldots \ldots \ldots \ldots \ldots \ldots \ldots \ldots \ldots \ldots \ldots \ldots \ldots, \quad$ XV

\section{Chapter 1 Introductory Material}

$1.1 \quad$ On the Evolution of the B.I.E.M./B.E.M. .................... 1

$1.2 \quad$ Elements of Nonsmooth Analysis .......................... 5

1.2.1 Elements of Nonsmooth-Convex Analysis .................... 5

1.2.2 Elements of Nonsmooth-Nonconvex Analysis ................... 13

$1.3 \quad$ Contact Problems. ...................................... 18

1.3.1 Monotone Multivalued Boundary and Interface Conditions.

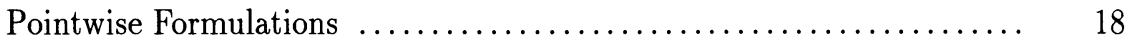

1.3.2 Extensions of the Monotone Multivalued Boundary

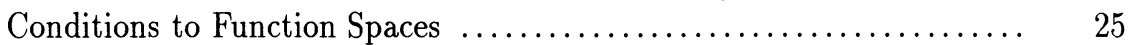

1.3.3 Nonmonotone Multivalued Boundary Conditions $\ldots \ldots \ldots \ldots \ldots \ldots \ldots . \ldots$

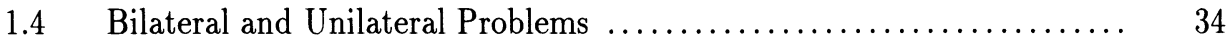

1.4.1 Variational Formulations ................................. 34

1.5 Existence Results for Variational and Hemivariational

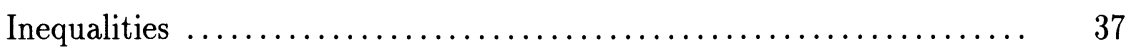

Chapter 2 The Direct and Indirect B.I.E.M. for Bilateral Problems

$2.1 \quad$ The B.V.P. of Linear Elasticity ............................ 43

2.2 The Method of Weighted Residuals .......................... 44

$2.3 \quad$ Generalized Variational Principles $\ldots \ldots \ldots \ldots \ldots \ldots \ldots \ldots \ldots \ldots \ldots . \ldots \ldots$

2.4 The Use of Reciprocal Theorems $\ldots \ldots \ldots \ldots \ldots \ldots \ldots \ldots \ldots \ldots \ldots . \ldots \ldots$

2.5 The Singularity Method (Indirect Method) $\ldots \ldots \ldots \ldots \ldots \ldots \ldots \ldots \ldots$

\section{Chapter 3 Boundary Integral Formulations for Some} Special Elastostatic B.V.Ps

3.1 Bending of Beams and Stretching of Bars .................. 65

$3.2 \quad$ A Direct B.I.E.M. for Kirchhoff Plates ...................... 71

3.3 A Direct B.I.E.M. for Reissner Plates ........................ 76

Chapter 4 On the Numerical Implementation of Boundary Element Equations

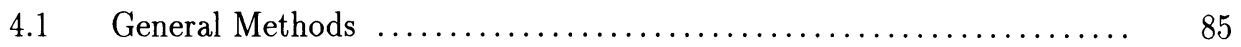

Kirchhoff Plate Boundary Element Equations by the
Point Collocation Method $\ldots \ldots \ldots \ldots \ldots \ldots \ldots \ldots \ldots \ldots \ldots \ldots \ldots \ldots \ldots \ldots$

4.3 The Galerkin B.E.M. in Reissner Plate Theory .................. 89 


\section{Chapter 5 Extension to Dynamic Problems}

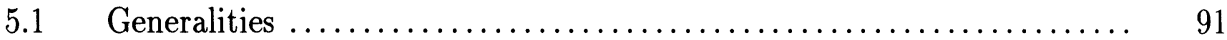

$5.2 \quad$ Steady State and Harmonic Problems $\ldots \ldots \ldots \ldots \ldots \ldots \ldots \ldots \ldots \ldots . . \ldots \ldots \ldots$

$5.3 \quad$ Numerical Applications ................................. $\quad 96$

5.3.1 Convergence Studies and Cut-off Errors ...................... 96

5.3.2 Noise Distribution Around 2-D Barrier Models ................. 101

5.4 Time Domain Formulation for Transient Problems ............... 105

5.4.1 Wave Propagation in 2-D Elastic Media ...................... 105

5.4.2 Sound Pressure Waves in 3-D Acoustics and Numerical Applications .................................. 110

\section{Chapter 6 Dynamic Interaction Problems}

6.1 Bilateral Coupling of Elastic Structures and Domains .............. 119

$6.2 \quad$ Fluid-Structure Interaction ................................. 127

6.3 Unilateral Contact Problems ................................ 132

6.3.1 Dynamical Problems. The Trial and Error Method ................ 132

6.3.2 Examples: Elastic Massive Foundations on Elastic ............... 138

Chapter 7 B.I. Formulations for the Signorini-Fichera Inequality Problem

7.1 Primal, Dual and Mixed Formulations of the B.V.P. .............. 147

7.2 Integral Formulation with Respect to the Tractions of the Contact Area ................................... 150

7.3 Integral Formulation with Respect to the Displacements of the Contact Area .................................... 153

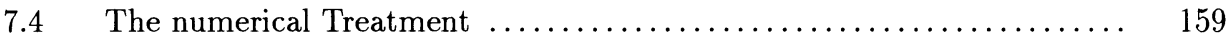

Chapter 8 Mathematical Study of the B.I. Formulations of the Signorini-Fichera B.V.P.

8.1 The Signorini-Fichera B.V.P: The Multivalued B.I.E with Respect to the Boundary Displacements ..................... 165

8.2 The Signorini-Fichera B.V.P: The Multivalued B.I.E with Respect to the Boundary Tractions

Chapter 9 Boundary Integral Formulation of the Frictional Unilateral Contact B.V.P.

9.1 The Signorini Problem with Given Friction. Primal Problem, Mixed Problem and Approximation Results .................. 177

9.2 The Derivation of a Multivalued B.I.E. for the Signorini Problem with Given Friction ............................ 180

9.3 On the Coulomb's Friction Problem. Numerical Results ............ 188 
Chapter 10 Boundary Integral Formulations for the Monotone Multivalued Boundary Conditions

10.1 Convex Problems. Primal, Dual and Mixed Problems .............. 193

10.2 The Multivalued B.I.E. with Respect to the Boundary Tractions on $\Gamma_{3}$

10.3 The Multivalued B.I.E. with Respect to the

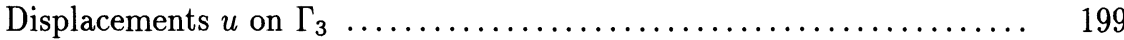

10.4 Certain Semicoercive Multivalued B.I.Es. Existence Results ......... 205

\section{Chapter 11 Elastodynamic Unilateral Problems.}

\section{A B.I.E. Approach}

11.1 The Time Discretization Scheme. Time-Difference Multivalued B.I.Es.

11.2 Numerical Applications

\section{Chapter 12 Nonconvex Unilateral Contact Problems}

12.1 A Boundary Integral Equation with Respect to the

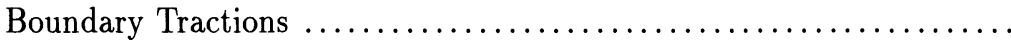

12.2 A Multivalued Boundary Integral Formulation with Respect to the Displacements on $\Gamma_{3}$.

12.3 On the Numerical Treatment of Nonmonotone (Zigzag)

Multivalued Contact Laws. A New Efficient Algorithm.

12.4 A Numerical Application: The Nonmonotone Friction and the Adhesive Contact Problem with Debonding.

A Fixed Point Type Algorithm.

12.5 A Short Note on Certain Coercive and Semicoercive Nonconvex Unilateral Contact Problems.

Chapter 13 Miscellanea

13.1 Unilateral Contact and Friction in Cracks. A General

Indirect B.I.E.M. for Inequality Problems .................... 247

13.2 Debonding and Delamination in Adhesively Bonded Cracks. ......... 250

13.3 Fractal Interfaces and Boundaries. ........................... 251

13.4 A Neurocomputing Approach to the Multivalued B.I.Es of the Inequality Contact Problems

13.5 A Supervised Learning Approach to the Parameter Identification in Contact Problems

References 


\section{Preface}

The fields of boundary integral equations and of inequality problems, or more generally, of nonsmooth mechanics, have seen, in a remarkably short time, a considerable development in mathematics and in theoretical and applied mechanics. The engineering sciences have also benefited from these developments in that open problems have been attacked succesfully and entirely new methodologies have been developed. The contact problems of elasticity is a class of problems which has offered many open questions to deal with, both to the research workers working on the theory of boundary integral equations and to those working on the theory of inequality problems. Indeed, the area of static and dynamic contact problems could be considered as the testing workbench of the new developments in both the inequality problems and in the boundary integral equations. This book is a first attempt to formulate and study the boundary integral equations arising in inequality contact problems.

The present book is a result of more than two decades of research and teaching activity of the first author on boundary integral equations and, of the second author, on inequality problems, as well as the outgrowth of seminars and courses for a variety of audiences in the Technical University of Aachen, the Aristotle University of Thessaloniki, the Universities of Bochum, of Hamburg and Braunschweig, the Pontificia Univ. Catolica in Rio de Janeiro etc.

The book is intended for a wide spectrum of readers, mathematicians and engineers alike. Chapters 2 to 6 concern the equality contact problems and have been written by the first author, whereas Chapters 7 to 13 concern the inequality contact problems and have been written by the second author, who also has the responsibility for sections $1.2 \div 1.5$ of Chapter 1 .

We wish to acknowledge the great assistance we received from Dr. Zervas who prepared in a very diligent way the final text with the LaTEX program, from Dr. E. Koltsakis, Dr. E. Mistakidis, Dr. O. Panagouli for the programming of the numerical applications of Chapters 7, 9,12 and 13 as well as for the preparation of the final figures, and from Prof. Z. Naniewicz for critically proofreading some parts of the book. We would also like to thank the editors of the ISNM series for including this volume in their series, our editors in Birkhäuser Verlag for their cooperation and all those who contributed to the emergence of the present volume.

Also, we must apologise to those whose work has been inadvertently neglected in compiling the references of this book. Moreover, we shall welcome all comments and corrections from readers.

H. Antes, P.D. Panagiotopoulos

Thessaloniki, June 1992 


\section{Introduction}

The aim of the present book is the formulation and study of boundary integral equation methods for static and dynamic contact problems. Both the cases of equality and inequality contact constraints are examined. Those of the first kind lead to classical bilateral problems expressed as variational equalities, whereas the others lead to unilateral problems expressed as variational inequalities in the case of monotone constraints, or as hemivariational inequalities in the case of nonmonotone constraints. The variational equalities give rise to classical boundary integral equations, whereas the variational inequalities and the hemivariational inequalities lead to multivalued boundary integral equations. In parallel to the formulation and the mathematical study, numerical examples help illustrate the presented theories.

In the first Chapter, after some historical information concerning the evolution of the boundary integral equation methods, we give some elements of nonsmooth convex and nonconvex analysis and certain propositions concerning minimization problems, variational inequalities and hemivariational inequalities. Moreover, the equality and inequality contact conditions are defined with respect to both the convex and the nonconvex constraint superpotentials.

In the second Chapter, direct and indirect boundary integral equation methods are presented for the case of equality constraints. Attention is paid to the method of weighted residuals, the use of reciprocal theorems and the singularity method.

In the third Chapter the above methods are illustrated with respect to certain problems from the theory of bars and of beams, and from the theory of Kirchhoff and Reissner plates.

The fourth Chapter deals with the numerical implementation of the boundary integral equations for equality problems. We pay attention to the point collocation method and to the Galerkin boundary element method.

Chapter five extends the results of the previous Chapters to dynamic equality problems. Both steady state and harmonic problems are treated and several numerical applications concerning transient problems and wave propagation problems are given.

Chapter six is the last Chapter dealing with equality problems. Here, certain dynamic interaction problems as the fluid-structure interaction problem and the unilateral contact problem, treated with trial and error methods, are presented.

The aim of Chapter seven is to smoothly introduce the reader into the area of inequality problems. In this Chapter we deal with the Signorini-Fichera B.V.P. We derive two multivalued integral equations holding on the boundary of the body. A numerical application illustrates the theory.

In the next Chapter the multivalued boundary integral equations derived in the previous Chapter are studied concerning the existence and uniqueness of their solutions.

Chapter nine deals with the frictional unilateral contact B.V.P. First the problem of given friction is studied, the corresponding boundary integral expressions are derived and are subsequently studied. Then Coulomb's friction problem is formulated. Numerical examples illustrate the theory. 
In Chapter ten certain general contact boundary conditions of monotone, possibly multivalued type, are considered. For them, two types of multivalued boundary integral equations are derived and studied. Here we deal both with the coercive and the semicoercive problem. For the latter, certain new necessary conditions and certain new sufficient conditions are obtained.

Chapter eleven deals with dynamic inequality problems. Using time discretization, a time difference boundary integral equation is obtained. Numerical applications concerning dynamic inequality problems illustrate the theory.

Chapter twelve deals with certain general contact boundary conditions of nonmonotone, possibly multivalued type. For these conditions, which are derived from nonconvex superpotentials, two multivalued boundary integral equations are formulated and studied. Existence results are obtained for both the coercive and the semicoercive case.

Chapter thirteen is the last Chapter of the book. Here we have included certain highly innovative topics. In the first section we deal with cracks having unilateral contact and friction interface conditions, in the second section with adhesively bonded cracks, in the third section we consider fractal interfaces subjected to unilateral contact and friction interface conditions and in the last two sections we deal with the treatment of the multivalued boundary integral equations, obtained in the previous Chapters for several inequality contact problems, in a neurocomputing environment. 


\section{Guidelines for the Reader. Abbreviations}

The choice of the material of Chapter 1 is governed by the requirements of the subsequent Chapters. We expect the reader to have some knowledge on basic functional analysis especially concerning the norms and certain elementary properties of Sobolev spaces, the Lax-Milgram theorem and the trace theorem. However this functional analysis is needed only for the Chapters 8,9 and for some parts of Chapters 10 and 12 . All propositions of nonsmooth analysis (convex and nonconvex) needed in this book are given in Ch.1. We intentionally include the numerical applications within each chapter in order to permit the reader to read seperately the chapters. The book is equally well accessible to a reader unfamiliar with functional analysis who is interested only in mechanics and in applications. In this case, proofs should be disregarded and the reader should understand the variational expressions in the "usual engineering sense" assuming that spaces $\left[H^{1}(\Omega)\right]^{3},\left[H^{1 / 2}(\Gamma)\right]^{3}$ etc. have simple three-dimensional spaces and the duality pairings $\langle\cdot, \cdot\rangle$ denote inner products.

Certain notations and abbreviations used throughout the text are listed here. All notations defined in the text are not given here. Throughout the book the summation convention with respect to a repeated index is employed. unless otherwise stated. Bold face letters denote vectors and matrices of discretized problems.

$\hat{=} \quad$ Definition

DOFs Degrees of Freedom

B.V.P. Boundary Value Problem

F.E.M. Finite Element Method

B.E.M. Boundary Element Method

B.I.E. Boundary Integral Equation

V.I. Variational Inequality

H.V.I. Hemivariational Inequality

L.C.P. Linear Complementarity Problem

Q.P.P. Quadratic Programming Problem

C.P.P. Convex Programming Problem

$f \quad$ Cauchy principal value

$\bar{A} \quad$ Closure of a set A

$\delta_{i j} \quad \delta_{i j}=\{0$ if $i \neq j\}$ Cronecker's delta

Due to the diversity of the results presented in this book, i.e. of theories of purely mechanical or mathematical origin, it was in some cases impossible to achieve a uniformity of notations. Therefore, we have tried to be as meticulus as we could in the definitions in order to avoid ambiguities. 